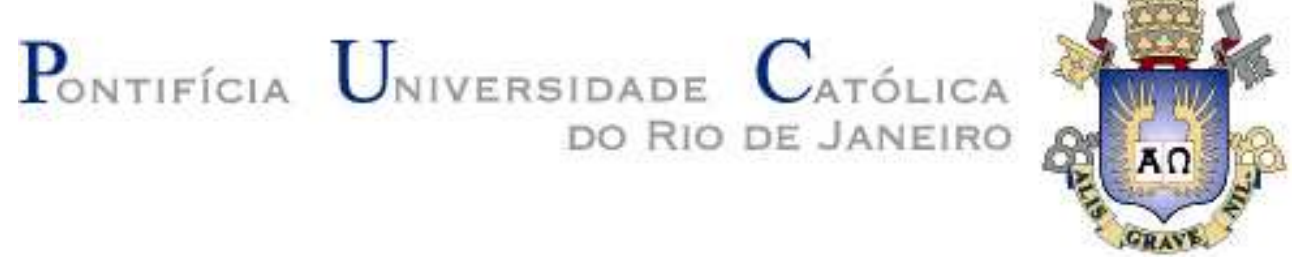

Larissa Azevedo Curty

\title{
Estudo Experimental dos Consoles Curtos de Concreto Armado Reforçados com Compósitos de Fibras de
} Carbono

Dissertação apresentada como requisito parcial para obtenção do título de Mestre pelo Programa de PósGraduação em Engenharia Civil da PUC-Rio.

Orientadores: Marta de Souza Lima Velasco Emil de Souza Sánchez Filho 
Pontifícia U Universidade Católica $_{\text {a }}$

DO RIO DE JANEIRO

\title{
Estudo Experimental dos Consoles Curtos de Concreto Armado Reforçados com Compósitos de Fibras de
}

Carbono

\begin{abstract}
Dissertação apresentada como requisito parcial para obtenção do título de Mestre pelo Programa de Pós-Graduação em Engenharia Civil da PUC-Rio. Aprovada pela Comissão Examinadora abaixo assinada.
\end{abstract}

Profa. Marta de Souza Lima Velasco Orientador Departamento de Engenharia Civil - PUC-Rio

Prof. Emil de Souza Sánchez Filho Co-orientador Programa de Pós-graduação em Engenharia Civil - UFF

Prof. Giuseppe Barbosa Guimarães Departamento de Engenharia Civil - PUC-Rio

Dr. Julio Jerônimo Holtz Silva Filho Avantec

Prof. Luiz Antonio Vieira Carneiro Instituto Militar de Engenharia - IME

José Eugênio Leal

Coordenador(a) Setorial do Centro Técnico Científico - PUC-Rio 
Todos os direitos reservados. É proibida a reprodução total ou parcial do trabalho sem autorização da universidade, da autora e do orientador.

\section{Larissa Azevedo Curty}

Graduou-se em Engenharia Civil na UENF (Universidade Estadual do Norte Fluminense Darcy Ribeiro).

Ficha Catalográfica

Curty, Larissa Azevedo.

Estudo experimental dos consoles curtos de concreto armado reforçados com compósitos de fibras de carbono/ Larissa Azevedo Curty ; orientadores: Marta de Souza Lima Velasco, Emil de Souza Sánchez Filho. - 2009.

$193 \mathrm{f}$ : : il (col) ; $30 \mathrm{~cm}$

Dissertação (Mestrado em Engenharia Civil) Pontifícia Universidade Católica do Rio de Janeiro, Rio de Janeiro, 2009.

Inclui bibliografia

1. Engenharia Civil - Teses. 2. Console curto. 3. Compósitos de fibra de carbono. 4. Reforço estrutural. 5. Análise experimental. 6. Concreto armado. I. Velasco, Marta de Souza Lima. II. Sánchez Filho, Emil de Souza. III. Pontifícia Universidade Católica do Rio de Janeiro. Departamento de Engenharia Civil. IV. Título. 


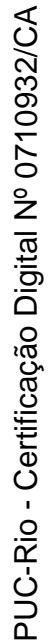

Aos meus pais 


\section{Agradecimentos}

A Deus.

Ao meu pai e amigo de profissão Emar por suas palavras de incentivo, carinho e amor.

A minha amada mãe Regina pelo sua compreensão e dedicação fundamentais para o término desta dissertação.

Ao meu querido namorado Magnus Thiago da Rocha Meira por sempre estar ao meu lado.

A minha irmã Luciana, meu cunhado Fernando e minha sobrinha Natália por todo carinho e amor.

As minhas avós Nair e Terezinha por sempre rezarem por mim.

À todos da minha família e amigos que me proporcionaram momentos descontraídos.

Aos orientadores Marta de Souza Lima Velasco e Emil de Souza Sánchez Filho pelos ensinamentos e orientação deste trabalho.

Aos amigos de profissão, Paulo César Azevedo, Nilson Costa Roberty, Maikon Pessanha, Cristiano Miller e Jean Crispim.

Aos amigos da PUC que ajudaram a realização deste trabalho, Arthur Medeiros, Fernando Ramires, João Krause, Juliana Vianna, Paula Coutinho, Paul Antezana e Suelen Rodrigues.

Aos professores e amigos da UENF (Universidade Estadual do Norte Fluminense), em especial aos professores Jean Marie Desir e Sérgio Luis Gonçales.

Aos amigos da Avantec Engenharia, em especial Júlio Holtz que me indicou o curso da pós-graduação da PUC-Rio. 
À Rita e aos funcionários do laboratório de estruturas PUC-Rio José Nilson, Euclides, Evandro e Haroldo pelos serviços prestados na execução dos ensaios.

À CONCRELAGOS pela doação do concreto utilizado para a confecção dos consoles.

A CAPES pelo apoio financeiro. 


\section{Resumo}

Curty, Larissa Azevedo; Velasco, Marta de Souza Lima; Sánchez Filho, Emil de Souza. Estudo Experimental dos Consoles Curtos de Concreto Armado Reforçados com Compósitos de Fibras de Carbono. Rio de Janeiro, 2009. 193p. Dissertação de Mestrado - Departamento de Engenharia Civil, Pontifícia Universidade Católica do Rio de Janeiro.

Este trabalho é uma pesquisa experimental realizada no Laboratório de Estruturas e Materiais da PUC-Rio, utilizando-se a técnica de aplicação do compósito de fibras de carbono (CFC) colados externamente em consoles curtos de concreto armado. Foram ensaiados seis consoles curtos, sendo: um de referência, três com reforço de CFC na horizontal e dois com reforço de CFC na diagonal. A resistência média do concreto aos 28 dias foi de $30 \mathrm{MPa}$. A seção transversal do pilar foi de $25 \mathrm{~cm} \times 50 \mathrm{~cm}$ e a seção do transversal console foi de $25 \mathrm{~cm} \times 37,5 \mathrm{~cm}$. O diâmetro da armadura tracionada em laço era de $10 \mathrm{~mm}$ e o diâmetro da armadura de costura era de $6,3 \mathrm{~mm}$. Os consoles foram instrumentados com extensômetros elétricos de resistência na armadura tracionada, no estribo, no concreto e no CFC. Os ensaios comprovaram um razoável desempenho dessa técnica de reforço. Os resultados experimentais foram comparados com os resultados obtidos no modelo de Bielas e Tirantes e no modelo cinemático da Teoria da Plasticidade, visando a comparação das forças verticais últimas teóricas e experimentais. Foi avaliado o ângulo de inclinação das bielas e o fator de efetividade da deformação específica no reforço de CFC.

\section{Palavras-chave}

Console Curto; Compósitos de Fibras de Carbono; Reforço Estrutural; Análise Experimental; Concreto Armado. 


\section{Abstract}

Curty, Larissa Azevedo; Velasco, Marta de Souza Lima; Sánchez Filho, Emil de Souza (Advisors). Experimental Study of Reinforced Concrete Short Corbels with Carbon Fiber Composites. Rio de Janeiro, 2009. 193p. Msc. Dissertation - Civil Engineering Departament, Pontifícia Universidade Católica do Rio de Janeiro.

This work is an experimental research of concrete short corbels wrapped with Carbon Fiber Reinforced Polymer (CFRP) strips. Different strengthening configurations were used. Was carried out on six corbels strengthened by CFRP. One control specimen without CFRP, three corbels with horizontal CFRP strips and two corbels with diagonal CFRP strips. The concrete had a 28 day compressive strength of $30 \mathrm{MPa}$. The column cross-section dimensions were 25 $\mathrm{cm} \times 50 \mathrm{~cm}$ and the corbel cross-section dimensions were $25 \mathrm{~cm} \times 37,5 \mathrm{~cm}$. The flexural reinforcement consisted of four deformed bars each of diameter $10 \mathrm{~mm}$ with four transverse bars of diameter $6,3 \mathrm{~mm}$. The corbels were instrumented with strain gages in flexural reinforcement, stirrup, concrete surface and CFRP strips. The analytical models based on Strut-and-Tie model and in the kinematic model of the Theory of Plasticity, allows one to determine the bearing capacity of corbels. The experimental values are then compared with the analytical results, showing good agreement. The strut angle and the strengthening effectiveness were evaluated.

\section{Keywords}

Corbel; Carbon Fiber Reinforced Polymer; Structural Strengthening; Experimental Analysis; Reinforced Concrete. 


\section{Sumário}

1 Introdução 24

1.1. Generalidades $\quad 24$

1.2. Objetivos 24

1.3. Organização do trabalho 25

2 Reforço Estrutural com Compósitos de Fibras de Carbono 26

2.1. Introdução 26

2.2. Tipos de Fibras $\quad 27$

2.3. Tipos de Resina $\quad 27$

2.4. Compósitos de Fibras de Carbono 28

2.5. Aplicações do CFC na Engenharia Civil 29

3 Revisão Bibliográfica $\quad 35$

3.1. Introdução 35

3.2. Considerações Gerais Sobre o Comportamento dos Consoles Curtos 35

3.2.1. Modos de Ruptura 35

3.3. Modelos Teóricos 38

3.3.1. Modelo de Bielas e Tirantes 38

3.3.1.1. Classificação das bielas e nós 39

3.3.1.2. Tirantes 42

3.3.1.3. Dimensionamento de Console 43

3.3.1.4. Recomendações de Normas e Autores $\quad 45$

3.3.2. Teoremas da Análise Limite 48

3.3.2.1. Modelo Cinemático 50

3.4. Revisão da Literatura 58

3.4.1. CORRY e DOLAN (2001) 58

3.4.2. ELGWADY et al. (2002) 60

3.4.3. SOUZA et al. (2006) 63

3.4.4. RIBEIRO et al. (2007) 67

4 Programa Experimental dos Consoles Curtos Reforçados com Tecido de Fibras de Carbono $\quad 70$ 
4.1. Introdução 70

4.2. Ensaios de Caracterização dos Materiais $\quad 70$

4.2.1. Tecido de Fibras de Carbono 70

4.2.1.1. Ensaio de Resistência à Tração do Compósito de Fibras de Carbono 71

4.2.2. Aço 73

4.2.3. Concreto 77

4.2.3.1. Resistência à Compressão 78

4.2.3.2. Resistência à Tração por Compressão Diametral de Corpos-de-Prova

Cilíndricos $\quad 79$

4.2.3.3. Módulo de Elasticidade e Diagrama Tensão Deformação Específica 80

4.3. Programa Experimental 83

4.3.1. Descrição dos Consoles 83

4.3.2. Características Geométricas $\quad 84$

4.4. Aplicação do Sistema de Reforço com CFC 86

4.5. Instrumentação $\quad 88$

4.5.1. Extensômetros Elétricos de Resistência 88

4.5.1.1. Aço 88

4.5.1.2. Concreto e CFC 88

4.5.2. Transdutor de Deslocamentos 90

4.6. Esquema de Ensaio 90

4.7. Execução dos Ensaios 92

5 Apresentação e Análise dos Resultados 94

5.1. Introdução 94

5.2. Rupturas dos Consoles 94

5.2.1. Modo de Ruptura 94

5.2.2. Força de Ruptura 96

5.3. Deformações Específicas nas Armaduras de Aço e CFC 98

5.3.1. Aço 98

5.3.2. CFC 102

5.4. Deformações Específicas na Biela 105

5.5. Análise do ângulo de Inclinação da Biela 106

5.6. Deslocamentos 109

5.7. Análise dos Modelos Teóricos 112

5.7.1. Modelo de Bielas e Tirantes 112

$\begin{array}{ll}\text { 5.7.2. Modelo Cinemático } & 114\end{array}$ 
5.8. Comparação entre os Valores Experimentais e os Valores Teóricos Obtidos pelo Modelo Cinemático e Modelo de Bielas e Tirantes

6 Conclusões e Sugestões para Trabalhos Futuros

6.1. Sugestões para trabalhos futuros

Referências Bibliográficas

Anexo A Registros Fotográficos

Anexo B Resultados dos Ensaios dos Consoles

Anexo C Rotinas de Cálculo das Forças Teóricas 


\section{Lista de figuras}

Figura $2.1 \quad-\quad$ Micrografia estrutural das fibras de carbono (http://www.carbonfiber.gr.jp/english/, visitado em 20/09/08). 26

Figura 2.2 - Fibras de vidro, aramida e carbono (http://www.fibertex.com.br/plasticoreforcado.htm, visitado em 20/09/08). 27 Figura 2.3 - Compósito de fibras de carbono (http://www.cesec.ufpr.br/pet/titulos/biblioteca/seminarios/arquivo seminario s/construcao civil/reforco estrutural com fibras de carbono.pdf, visitado em 20/09/08).

Figura 2.4 - Ampliação em microscópio eletrônico da matriz polimérica (http://www.cesec.ufpr.Br/pet/titulo/biblioteca/seminarios/arquivo seminarios /construcao civil/reforco estrutural com fibras de carbono.pdf, visitado em 20/09/08).

29

$\begin{array}{lllllll}\text { Figura } & 2.5 & - & \text { Ponte } & \text { Storchen } & \text { na } & \text { Suíça }\end{array}$

(http://www.compositesworld.com/ct/issues/2006/February/1180/3). 29

Figura 2.6 - Cabo de compósito de fibras de carbono utilizado na Ponte Storchen em Switzerland

(http://www.compositesworld.com/ct/issues/2006/February/1180/3). 30

Figura $2.7 \quad-\quad$ Reabilitação de ponte utilizando CFC (http://www.compositesworld.com/ct/issues/2006/April/1240). 30

Figura 2.8 - Laje e viga reforçada no viaduto de Santa Tereza (http://www.cesec.ufpr.Br/pet/titulo/biblioteca/seminarios/arquivo seminarios /construcao civil/reforco estrutural com fibras de carbono.pdf, visitado em 20/09/08).

Figura 2.9 - Reforço em console (http://www.kcg.cc/index.php?id=117 visitado em 18/05/2009).

Figura 2.10 - Reforço á flexão e à força cortante de viga externa do Edifício da Alcan Alumino do Brasil em Ouro Preto (http://www.cesec.ufpr.Br/pet/titulo/biblioteca/seminarios/arquivo seminarios /construcao civil/reforco estrutural com fibras de carbono.pdf, visitado em 20/09/08).

Figura 2.11 - Reforço de pilares retangulares e de colunas (http://media.wiley.com/product data/excerpt/61/04716812/0471681261.pdf, visitado em 20/09/08). 
Figura 2.12 - Reforço da Torre da Rede Globo de Televisão no Rio de Janeiro RJ

(http://www.cesec.ufpr.Br/pet/titulo/biblioteca/seminarios/arquivo seminarios /construcao civil/reforco estrutural com fibras de carbono.pdf, visitado em 20/09/08).

Figura 2.13 - Fábrica de Laticínios Itambé em Sete lagoas MG (http://www.cesec.ufpr.-

Br/pet/titulo/biblioteca/seminarios/arquivo seminarios/construcao civil/reforc o estrutural com fibras de carbono.pdf).

Figura 2.14 - Fábrica de Laticínios Itambé em Sete lagoas MG, onde foi executado um reforço ao redor dos furos na laje (http://www.cesec.ufpr.Br/pet/titulo/biblioteca/seminarios/arquivo seminarios/construcao civil/reforco estrutural com fibras de carbono.pdf, visitado em 20/09/08).

Figura 2.15 - Reforço da viga à flexão e à força cortante na Fundação Mineira de $\begin{array}{lllll}\text { Educação } & \text { e } & \text { Cultura } & - & \text { FUMEC }\end{array}$ (http://www.cesec.ufpr.Br/pet/titulo/biblioteca/seminarios/arquivo seminarios /construcao civil/reforco estrutural com fibras de carbono.pdf, visitado em 20/09/08).

Figura 3.1 - Trajetórias de tensões (FRANZ, 1970). 36 Figura 3.2 - Modos de ruptura: (a) ruptura por flexão; (b) ruptura por fendilhamento da biela; (c) ruptura por cisalhamento.

Figura 3.3 - Modos de ruptura: (a) falha na ancoragem; (b) força horizontal; (c) esmagamento do concreto. $\quad 37$

Figura 3.4 - Exemplos de regiões D (SCHÄFER e SCHLAICH,1988). 38 Figura 3.5 - Configurações típicas de campos de tensão de compressão (SCHÄFER e SCHLAICH,1988). 40

Figura 3.6 - Tipos de nós: (a) nó CCC; (b) nó CCT; (c) nó CTT; (d) nó TTT (ACI $-318,2008)$.

Figura 3.7 - (a) Modelo de Bielas e Tirantes; (b) Configuração da treliça do modelo de Bielas e Tirantes.

Figura 3.8 - Modelo de Bielas e Tirantes com a parcela do CFC; (a) CFC na horizontal; (b) CFC na diagonal.

Figura 3.9 - Modelo de Bielas e Tirantes para console curto (NBR 6118:2004). 46

Figura 3.10 - Armadura típica de console curto (NBR 6118:2004).

Figura 3.11 - Critérios para armadura do tirante (LEONHARDT e MÖNNIG, 
1978).

48

Figura 3.12 - Posição da placa de força (LEONHARDT e MÖNNIG, 1978). 48 Figura 3.13 - Armaduras de tração: (a) para uma força axial de compressão pequena; (b) para uma força axial de compressão grande (LEONHARDT e MÖNNIG, 1978). 48

Figura 3.14 - Soluções usando-se os teoremas da Análise Limite. 50

Figura 3.15 - Parâmetros geométricos do console curto de concreto armado. 51 Figura 3.16 - Parâmetros geométricos do console curto de concreto armado reforçado com CFC. 51

Figura 3.17 - Parâmetros geométricos do console curto de concreto armado com $\mathrm{X}=0$. 55

Figura 3.18 - Geometria e armadura do console (CORRY e DOLAN, 2001). 58

Figura 3.19 - Descolamento do reforço (CORRY e DOLAN, 2001). 59

Figura 3.20 - Dimensões (centímetro) dos consoles curtos ensaiados por ELGWADY et al. (2002).

Figura 3.21 - Consoles ensaiados: a) console de referência (CONT); b) 11HOR; 61

c) 21HOR; d) 61DIG; e) 82 HAD; f) 32 HOR; ELGWADY et al. (2002). 61 Figura 3.22 - Dimensões dos consoles curtos ensaiados por SOUZA et al. (2006). 64

Figura 3.23 - Descrição consoles (Ribeiro et al., 2007). 68 Figura 3.24 - (a) Armadura dos consoles; (b) realização do ensaio (RIBEIRO et al.,2007). 69

Figura 4.1 - Dimensões dos corpos-de-prova para ensaio à tração do CFC de acordo 71 com a ASTM D 3039 / D 3039 M. 71

Figura 4.2 - (a) Corpos-de-prova de CFC, (b) Ensaios dos corpos-de-prova (SPAGNOLO, 2008).

Figura 4.3 - Ensaio à tração dos corpos-de-prova: (a) Laboratório de Estruturas e Materiais; (b) ITUC. 74

Figura 4.4 - Diagrama tensão x deformação específica para as barras de $\phi$ 5,0 $\mathrm{mm}$.

Figura 4.5 - Diagrama tensão x deformação específica para as barras de $\phi 6,3$ $\mathrm{mm}$.

Figura 4.6 - Diagrama tensão x deformação específica para as barras de $\phi 10,0$ $\mathrm{mm}$. 
Figura 4.7 - Diagrama tensão x deformação específica para as barras de $\phi 12,5$ $\mathrm{mm}$.

Figura 4.8 - Variação da resistência média à compressão do concreto para diferentes idades.

Figura 4.9 - Ensaio de resistência à tração do concreto por compressão diametral.

Figura 4.10 - Diagrama tensão x deformação específica do corpo-de-prova 1.81

Figura 4.11 - Diagrama tensão x deformação específica do corpo-de-prova 2.82

Figura 4.12 - Diagrama tensão x deformação específica do corpo-de-prova 3.82

Figura 4.13 - Fluxograma das séries dos consoles. 83

Figura 4.14 - Geometria dos consoles (medidas em cm). 84

Figura 4.15 - Armadura de aço dos consoles. 85

Figura 4.16 - Posições do reforço em CFC: série H e série D. 86

Figura 4.17 - Preparação das superfícies. $\quad 87$

Figura 4.18 - Instrumentação nas armaduras internas de aço. 88

Figura 4.19 - Posições das rosetas no CFC dos consoles das séries H e D (medidas em centímetros).

Figura 4.20 - Posições dos ERR no CFC dos consoles das séries H e D (medidas em centímetros).

Figura 4.21 - Posições das réguas de deslocamento linear (medidas em centímetros). 90

Figura 4.22 - Esquema do ensaio. $\quad 91$

Figura 4.23 -Esquema de ensaio do console RUD2. 91

Figura 4.24 - Consoles ensaiados. 93

Figura 5.1 - Tipos de fissuras. 95

Figura 5.2 - Comparação entre as forças de fissuração. 95

Figura 5.3 - (a) ruptura por destacamento da fibra; (b) ruptura por fendilhamento da biela. $\quad 96$

Figura 5.4 - Comparação entre as forças últimas de ruptura. 97

Figura 5.5 - Força x deformação específica das armaduras internas do console de referência. $\quad 98$

Figura 5.6 - Força x deformação específica das armaduras internas do console $\mathrm{RUH1}$.

Figura 5.7 - Força x deformação específica das armaduras internas do console $\mathrm{RUH} 2$.

Figura 5.8 - Força x deformação específica das armaduras internas do console 
RUH3.

100

Figura 5.9 - Força x deformação específica das armaduras internas do console

RUD1.

100

Figura 5.10 - Força x deformação específica das armaduras internas do console

RUD2.

101

Figura 5.11 - Força x deformação específica do CFC do console RUH1. 102

Figura 5.12 - Força x deformação específica do CFC do console RUH2. 102

Figura 5.13 - Força x deformação específica do CFC do console RUH3. 103

Figura 5.14 - Força x deformação específica do CFC do console RUD1. 103

Figura 5.15 - Força x deformação específica do CFC do console RUD2. 104

Figura 5.16 - Ângulo $\theta_{C R}$ medido por meio digital. 107

Figura 5.17 - llustração do ângulo da biela. 107

Figura 5.18 - Ângulo da biela vs força: (a) console de referência; (b) console

RUD1; (c) console RUD2; (d) console RUH1; (e) console RUH2; (f) console

RUH3. 108

Figura 5.19 - Esquema dos deslocamentos dos consoles. 110

Figura 5.20 - Força x deslocamentos do console de referência. 110

Figura 5.21 - Força x deslocamentos do console RUH1. 110

Figura 5.22 - Força x deslocamentos do console RUH2. 111

Figura 5.23 - Força x deslocamentos do console RUH3. 111

Figura 5.24 - Força x deslocamento do console RUD1. 111

Figura 5.25 - Força x deslocamento do console RUD2. 112

Figura 5.26 - Representação das armaduras analisadas por meio do modelo de

Bielas e Tirantes. 113

Figura 5.27 - Comparação das razões entre a força última experimental e as forças últimas teóricas obtidas nos dois modelos teóricos. 117

Figura A.1 - Tecido de fibras de carbono. 124

Figura A.2 - Resina epoxídica componentes A e B. 124

Figura A.3 - Rolo: material utilizado para aplicação da resina. 125

Figura A.4 - Armaduras dos consoles. 125

Figura A.5 - EER sendo colado na armadura interna. 126

$\begin{array}{ll}\text { Figura A.6 - Formas e armaduras. } & 126\end{array}$

Figura A.7 - Montagem dos consoles antes do recebimento do concreto. 127

Figura A.8 - Enchimento do carrinho de mão com o concreto do caminhão betoneira.

Figura A.9 - Vista superior de todos os consoles preparados para receber o 
concreto.

Figura A.10 - Consoles concretados. 128

Figura A.11 - Transporte das peças. 129

Figura A.12 - Arrumação das peças a serem ensaiadas. 129

Figura A.13 - Série H. 130

Figura A.14 - Detalhe da roseta. 130

Figura A.15 - Detalhe do console RUD1. 131

Figura A.16 - Console RUD2, ruptura do CFC na face lisa. 131

Figura A.17 - Console RUD2, ruptura do CFC na face rugosa. 132

Figura A.18 - Ensaio do console RUH1. 132

Figura A.19 - Ensaio do console RUH2, descolamento do CFC na face rugosa.

Figura A.20 - Detalhe do console RUH2. 133

Figura A.21 - Ensaio do console RUH3. 134

Figura A.22 - Bombas hidráulicas de pressão controlada, marca AMSLER. 134

Figura A.23 - Prensa Contenco com capacidade de 2400kN. 135

Figura A.24 - Atuadores Hidráulicos. 135 


\section{Lista de tabelas}

Tabela 3.1 - Valores de $\beta_{s}$. $\quad 41$

Tabela 3.2 - Valores de $\beta_{n}$. 42

Tabela 3.3 - Resultados experimentais e teóricos. 63

Tabela 3.4 - Dimensionamento no Estado Limite Último. 65

Tabela 3.5 - Largura da biela e tensão. 65

Tabela 3.6 - Características dos consoles. $\quad 68$

Tabela 3.7 - Força e modo de ruptura. 69

Tabela 4.1 - Geometria dos corpos-de-prova de CFC recomendada pela ASTM D $3039 / D 3039$ M.

Tabela 4.2 - Resultados dos ensaios de resistência à tração dos corpos-deprova com uma camada de CFC. $\quad 73$

Tabela 4.3 - Resultados dos ensaios das barras de aço. 75

Tabela 4.4 - Consumo de materiais por $\mathrm{m}^{3}$ de concreto. 77

Tabela 4.5 - Valores médios da resistência à compressão do concreto. $\quad 79$

Tabela 4.6 - Resultados dos ensaios de resistência à tração do concreto por compressão diametral. $\quad 80$

Tabela 4.7 - Resultados dos ensaios de módulo de elasticidade. 81

Tabela 5.1 - Força $(\mathrm{kN})$ das primeiras fissuras dos consoles. 95

Tabela 5.2 - Valores da força última. $\quad 97$

Tabela 5.3 - Deformações específicas efetivas nas armaduras de aço. 101

Tabela 5.4 - Deformações específicas efetivas nos reforços do CFC. 104

Tabela 5.5 - Tensão na armadura nos reforços de CFC e fator de efetividade.

105

Tabela 5.6 - Deformações específicas lidas na superfície do concreto dos $\begin{array}{ll}\text { consoles para força de ruptura. } & 106\end{array}$

Tabela 5.7 - Ângulos $\theta_{c r}$ e $\theta_{\varepsilon}$. 109

Tabela 5.8 - Resultados das forças últimas do modelo de Bielas e Tirantes. 113

Tabela 5.9 - Variáveis do modelo cinemático. 115

Tabela 5.10 - Valores das dimensões x e y. 115

Tabela 5.11 - Força vertical última. $\quad 116$

Tabela B.1 - Leitura dos TD e extensômetros colados no aço do console de referência. 
Tabela B.2 - Leitura dos extensômetros colados na superfície do concreto do console de referência. 138

Tabela B.3 - Leitura dos TD e extensômetros colados no aço do console RUH1.

Tabela B.4 - Leitura dos extensômetros colados na superfície do concreto do console RUH1.

Tabela B.5 - Leitura dos extensômetros colados no CFC do console RUH1. 144

Tabela B.6 - Leitura dos TD e extensômetros colados no aço do console RUH2.

Tabela B.7 - Leitura dos extensômetros colados na superfície do concreto do console RUH2.

Tabela B.8 - Leitura dos extensômetros colados no CFC do console RUH2. 150

Tabela B.9 - Leitura dos TD e extensômetros colados no aço do console RUH3.

152

Tabela B.10 - Leitura dos extensômetros colados na superfície do concreto do console RUH3.

154

Tabela B.11 - Leitura dos extensômetros colados no de CFC do console RUH3.

Tabela B.12 - Leitura dos TD e extensômetros colados no aço do console RUD1.

158

Tabela B.13 - Leitura dos extensômetros colados na superfície do concreto do console RUD1.

Tabela B.14 - Leitura dos extensômetros colados no CFC do console RUD1. 162

Tabela B.15 - Leitura dos TD e extensômetros colados no aço do console RUD2.

Tabela B.16 - Leitura dos extensômetros colados na superfície do concreto do console RUD2.

Tabela B.17 - Leitura dos extensômetros colados no CFC do console RUD2. 168 


\section{Lista de símbolos}

\section{Romanos}

a Distância da face do pilar até o eixo de aplicação da força externa

$A_{f} \quad$ Área da seção transversal do reforço

$A_{s} \quad$ Área de aço

b Largura do console

$c_{1} \quad$ Distância do bordo da placa de apoio até o bordo do pilar

d $\quad$ Altura útil

$d_{s} \quad$ Distância da zona comprimida até a armadura principal

$d_{i} \quad$ Distância da zona comprimida até a camada i de armadura

$d_{f} \quad$ Braço de alavanca do reforço

$E_{c} \quad$ Módulo de elasticidade do concreto

$E_{f} \quad$ Módulo de elasticidade do reforço

$E_{f, e f .} \quad$ Módulo de elasticidade efetiva do CFC

$E_{s} \quad$ Módulo de elasticidade do aço

$E_{\mathrm{sec}, 0,3} \quad$ Módulo de elasticidade secante

$f_{c} \quad$ Resistência do concreto à compressão

$f_{c e} \quad$ Resistência efetiva das bielas e dos nós

$f_{f} \quad$ Resistência à tração do reforço

$f_{f, e} \quad$ Resistência efetiva à tração do reforço

$f_{f, u} \quad$ Resistência última à tração do reforço

$f_{t} \quad$ Resistência do concreto à tração

$f_{t, D} \quad$ Resistência à tração do concreto por compressão diametral

$f_{y} \quad$ Resistência de escoamento do aço

$f_{y i} \quad$ Resistência de escoamento do aço na camada i

$f_{y d} \quad$ Resistência de escoamento de cálculo do aço

$F_{C F C} \quad$ Força resistida do reforço

$F_{\text {máx }, f} \quad$ Força máxima no reforço

$F_{n} \quad$ Força nominal resistente da biela, tirante ou nó 


\begin{tabular}{|c|c|}
\hline$F_{x f}$ & Força na direção x do reforço \\
\hline$h$ & Altura total do console \\
\hline$h^{\prime}$ & Recobrimento da armadura do tirante \\
\hline$H$ & Força na horizontal \\
\hline$H_{u}$ & Força na horizontal teórica última \\
\hline$l_{i}$ & Comprimento do elemento i \\
\hline$T_{i}$ & Força na biela ou no tirante i \\
\hline$T$ & Força atuante no tirante \\
\hline$V$ & Força vertical atuante \\
\hline$V_{\text {exper. }}$ & Força vertical experimental \\
\hline$V_{\text {teorica }}$ & Força vertical teórica \\
\hline$V_{u}$ & Força vertical última \\
\hline$V_{u, r e f}$ & Força vertical última do console de referência \\
\hline$x$ & Posição horizontal da fissura inclinada \\
\hline$y$ & Posição vertical da fissura inclinada \\
\hline$z$ & Braço de alavanca \\
\hline$\dot{w}$ & Rotação virtual \\
\hline$W_{E X T}$ & Trabalho virtual externo \\
\hline$W_{I N T}$ & Trabalho virtual interno \\
\hline
\end{tabular}




\section{Gregos}

$\alpha \quad$ Ângulo entre a força de tração e a biela comprimida

$\alpha^{\prime} \quad$ Inclinação do reforço diagonal do CFC

$\beta_{n} \quad$ Fator determinado pelo tipo de nó

$\beta_{s} \quad$ Fator determinando pelo tipo de biela

$\varepsilon_{1,2} \quad$ Deformações específicas principais

$\varepsilon_{x} \quad$ Deformação específica do concreto na direção $\mathrm{x}$

$\varepsilon_{y} \quad$ Deformação específica do concreto na direção y

$\varepsilon_{45^{\circ}} \quad$ Deformação específica do concreto na diagonal à $45^{\circ}$

$\varepsilon_{c} \quad$ Deformação específica do concreto

$\varepsilon_{c, \text { máx }} \quad$ Deformação especifica máxima do concreto

$\varepsilon_{f, e} \quad$ Deformação específica efetiva da fibra

$\varepsilon_{f, \text { ef. }} \quad$ Deformação específica efetiva do CFC

$\varepsilon_{i} \quad$ Deformação específica média do elemento i

$\varepsilon_{f, u} \quad$ Deformação específica última do CFC

$\varepsilon_{s, u} \quad$ Deformação específica última do aço

$\phi_{r} \quad$ Coeficiente de redução para bielas, nós e tirantes

$\phi \quad$ Diâmetro da barra de aço

$\gamma_{f} \quad$ Fator de ponderação da força

$v_{c} \quad$ Fator de efetividade à compressão do concreto

$v_{f} \quad$ Fator de efetividade do CFC

$v_{t} \quad$ Fator de efetividade à tração do concreto

$\theta \quad$ Ângulo de inclinação da biela de concreto (campo de compressão)

$\theta_{C R} \quad$ Ângulo de inclinação fissura

$\theta_{e} \quad$ Ângulo de deformação específica principal

$\rho \quad$ Taxa de armadura

$\varpi_{\text {EXT }} \quad$ Trabalho virtual externo

$\varpi_{\text {INT }} \quad$ Trabalho virtual interno

$\delta^{\prime} \quad$ Deslocamento horizontal no topo do pilar

$\delta " \quad$ Deslocamento vertical na extremidade do console 


\section{Lista de abreviaturas}

ABNT Associação Brasileira de Normas Técnicas

$\mathrm{ACl}$

American Concrete Institute

ASTM

American Society for Testing and Materials

CEB

Comité Euro-International du Béton

CFC

Compósitos de Fibras de Carbono

CFRP

Carbon Fiber Reinforced Polymer

CCC

Nó que recebe três barras comprimidas

CCT

Nó que recebe duas barras comprimidas e uma tracionada

CTT

Nó que recebe uma barra comprimida e duas tracionadas

EER

Extensômetro elétricos de resistência

ITUC

Instituto Tecnológico da PUC-Rio

LEM

Laboratório de Estruturas e Materiais

NBR

Norma Brasileira

PUC-RIO

Pontifícia Universidade Católica do Rio de Janeiro

TD

Transdutor de deslocamento

TTT

Nó que recebe três barras tracionadas 